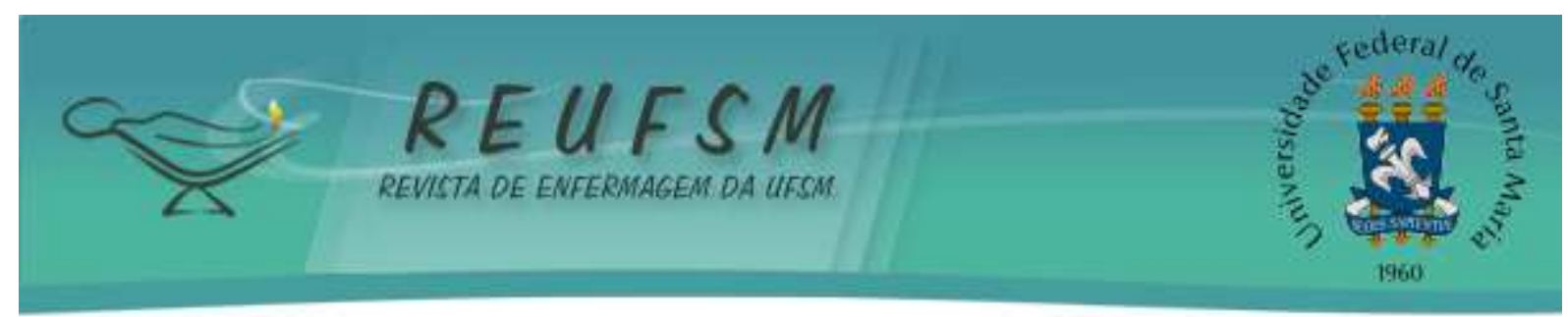

\title{
ARTIGO DE REVISÃO EL MOVIMIENTO ANTI-VACUNAS COMO PROBLEMA DE SALUD PÚBLICA: UNA REVISIÓN INTEGRATIVA DE LA LITERATURA
}

\section{O MOVIMENTO ANTI-VACINAÇÃO COMO PROBLEMA DE SAÚDE PÚBLICA: UMA REVISÃO INTEGRATIVA DA LITERATURA}

\section{ANTI-VACCINATION MOVEMENT AS A PUBLIC HEALTH PROBLEM: AN INTEGRATIVE LITERATURE REVIEW}

\author{
Jose Antonio Ponce-Blandón ${ }^{1}$ \\ Marina Díaz-Ruiz ${ }^{2}$ \\ Manuel Pabón-Carrasco ${ }^{3}$ \\ Mercedes Lomas-Campos ${ }^{4}$
}

Doi: $10.5902 / 2179769229296$

RESUMEN: Objetivo: Conocer la situación actual de los grupos del movimiento antivacunas, su presencia social y comprender mejor los motivos que llevan a las personas a decidir no vacunar a sus hijos. Metodología: Los artículos fueron seleccionados de noviembre de 2015 hasta mayo de 2016, por medio de una revisión integrativa. Las fuentes de datos consultadas fueron: PubMed, Scielo, Scopus, Cochrane Plus y CINAHL. La calidad de los estudios fue evaluada por medio de la escala Scottish Intercollegiate Guidelines Network (SIGN). Resultados: 587 artículos fueron identificados, de los cuales seleccionados 22. Las razones del rechazo a las vacunas varían desde motivos filosóficos o temor de sobrecargar el sistema inmunitario, hasta miedo de los efectos secundarios o una errónea percepción de bajo riesgo de enfermarse. Conclusiones: La vacunación debe ser entendida como un derecho fundamental de cada niño, además de eso con las informaciónes adecuadas y la relación salud-padres/paciente pueden ser obtenidos grandes resultados.

Descriptores: Vacunas; Vacunación; Negativa del paciente al tratamiento; Vacunación masiva; Padres

RESUMO: Objetivo: Conhecer a situação atual dos grupos do movimento anti-vacinas, conhecer sua presença social e entender melhor as razões que levam as pessoas a decidir não vacinar seus filhos. Metodologia: Os artigos foram selecionados de novembro de 2015 a maio de 2016, por meio de uma revisão integrativa. As fontes de dados consultadas foram: PubMed, Scielo, Scopus, Cochrane Plus e CINAHL. A qualidade dos estudos foi avaliada usando a Scottish Intercollegiate Guidelines Network (SIGN). Resultados: 587 artigos foram encontrados, finalmente selecionados 22. Razões para a rejeição de vacinas variam de razões filosóficas ou medo de sobrecarregar o sistema imunológico, medo de efeitos colaterais ou uma percepção equivocada de baixo risco de adoecer. Conclusões: A vacinação deve ser

\footnotetext{
${ }^{1}$ Professor de Promoção da Saúde e Diretor do Centro Universitário de Enfermagem da Cruz Vermelha. Doutor em Ciências da Saúde. Centro Universitário de Enfermagem da Cruz Vermelha. Universidade de Sevilha. Sevilha (Espanha). japonce@cruzroja.es

${ }^{2}$ Enfermeira. Mestrado em Ciências em Saúde. Centro Universitário de Enfermagem da Cruz Vermelha. Universidade de Sevilha. Sevilha (Espanha). marina_294@hotmail.com

${ }^{3}$ Professor de Estatística e TICs e Coordenador Acadêmico do Centro Universitário de Enfermagem da Cruz Vermelha. Doutor em Ciências da Saúde. Centro Universitário de Enfermagem da Cruz Vermelha. Universidade de Sevilha. Sevilha (Espanha). mpabon@cruzroja.es

${ }^{4}$ Professor de Promoção da Saúde. Doutor em Ciências da Saúde. Faculdade de Enfermagem, Fisioterapia e Podologia. Universidade de Sevilha. Sevilha (Espanha). mlomas@us.es
} 


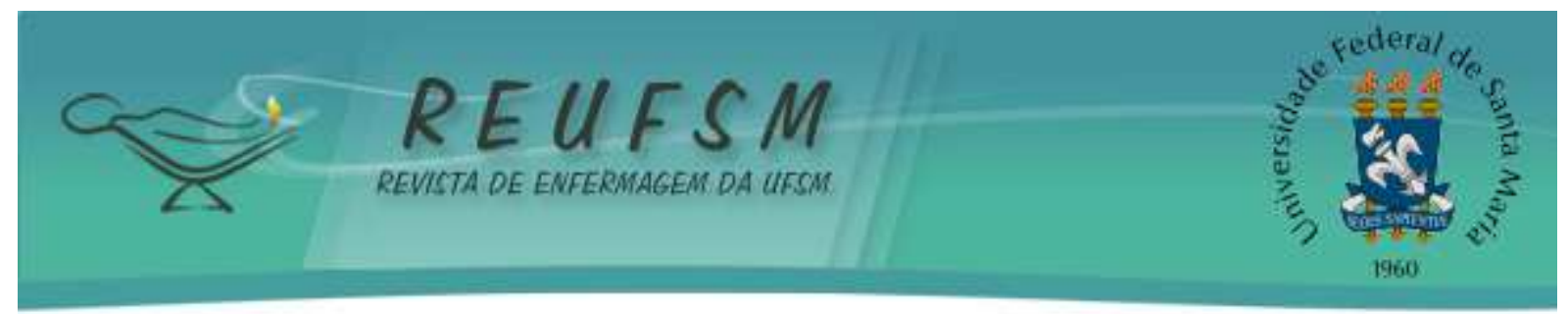

entendida como um direito fundamental de cada criança, sabendo que com informação adequada e relação de saúde- pais e mães / paciente, podem ser obtidos grandes resultados. Descritores: Vacinas; Vacinação; Recusa do paciente ao tratamento; Vacinação em massa; Pais

ABSTRACT: Aim: To analyze current literature about the situation of anti-vaccine movement groups and their current social presence, and to better understand the reasons why people decide not to vaccinate their childen. Methodology: A screening of articles was carried out, from November 2015 to May 2016, through an integrative review. The sources of data consulted were: PubMed, Scielo, Scopus, Cochrane Library Plus and CINAHL. The quality of the studies was assessed using the Scottish Intercollegiate Guidelines Network (SIGN). Results: A total of 587 articles was found, and 22 were selected, finally. The reasons for rejection of vaccines vary from philosophical reasons or fear of overloading the immune system to fear of side effects or a mistaken perception of low risk of disease. Conclusions: Vaccination should be understood as a fundamental right of each child, also knowing that with good information, communication and health relationship-parent / patient, great results can be obtained.

Descriptors: Vaccines Vaccination; Treatment Refusal; Massive vaccination; Parents

\section{INTRODUCCIÓN}

El polémico artículo publicado en la revista The Lancet sobre el estudio del cirujano e investigador Andrew Wakefield en el que se nombra por primera vez una posible asociación entre la vacuna triple vírica y el autismo, junto a la posterior retracción de la revista (el Colegio de Médicos británico y el periódico The Sunday Times demostraron la falsedad de tal relación entre vacuna y enfermedad, probándose el gran fraude que escondía su estudio) y la consecuente retirada del título de Wakefield ${ }^{1-2}$ podría haber quedado como una anécdota, pero la realidad fue que a partir de ese momento fueron muchos los padres que comenzaron a plantearse si la vacuna triple vírica era realmente necesaria y eficaz, a la vez que con el tiempo estas dudas empezaron a afectar también al resto de vacunas, convirtiéndose Wakefield en líder de un movimiento social de rechazo a las vacunas. ${ }^{2}$

A pesar de que han pasado 6 años de la retirada de dicho artículo, el movimiento anti-vacunas persiste en la sociedad actual, y esto se debe en gran medida a que los adeptos pueden ampararse en la persistente existencia de brotes epidémicos de enfermedades infecciosas prevenibles con las vacunas. A ello se le suman debates actuales como el que afecta a la vacuna del virus del papiloma humano (una de las vacunas existentes contra este virus, Gardasil@ de Merck \& Co., ha sido denunciada por numerosos padres que aseguran que sus hijas han sido gravemente afectadas por los efectos secundarios de tal vacuna) ${ }^{3}$ o las dudas existentes sobre la efectividad de la vacunación antigripal. Todo ello no ha hecho sino aumentar la credibilidad de este movimiento de rechazo a la vacunación. ${ }^{2}$ 


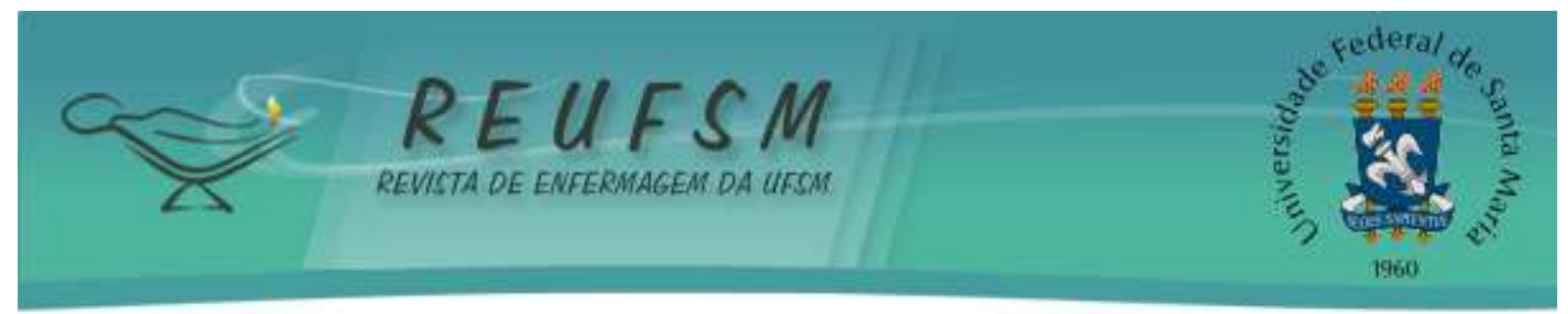

Por tanto, todas estas circunstancias podrían justificar el estado actual epidemiológico de algunas enfermedades infecciosas prevenibles mediante vacunación y las aún bajas tasas de vacunación para algunas vacunas, $\mathrm{y}$, aunque no se puede cargar todas las culpas de estos problemas al rechazo a la vacunación, sí que es una de las razones de mayor peso. ${ }^{2}$

En el Reino Unido (país donde se ubica la sede de la revista The Lancet y país de Wakefield), en 1997, la tasa de niños vacunados con la triple vírica era de un $92 \%$. Al año siguiente, esta cifra disminuyó gravemente y en 2002 se situó en un 83\%. Si se tiene en cuenta que se debe alcanzar un $92-95 \%$ de vacunados para que la inmunidad de grupo sea efectiva para esta vacunación, el aumento en la incidencia de brotes epidémicos es explicable. Esta situación descrita en el Reino Unido puede extrapolarse a otros países y otras comunidades, donde los números que se manejan son similares. ${ }^{2}$

En líneas generales, se puede concluir que el auge de los movimientos antivacunas está provocando que aparezcan brotes importantes de enfermedades que han sido tradicionalmente controladas con la vacunación. Gracias a la primovacunación con las posteriores dosis de recuerdo, la Medicina había conseguido disminuir la incidencia o incluso erradicar enfermedades infecciosas que anteriormente habían sido causa de un gran número de muertes, como por ejemplo la Difteria o el Sarampión. De este modo, en el caso del sarampión, la incidencia de casos había disminuido hasta prácticamente el nivel mínimo, lo cual ha hecho pensar a gran parte de la población que estas enfermedades ya no existían y que, por tanto, no es necesario vacunar a sus hijos contra algo que suponen ellos que no exíste. Por consiguiente, los nuevos brotes aparecidos resultan más bruscos, y como prueba de ello es destacable el caso que se produjo a comienzos de 2015, cuando la prensa mundial se hacía eco de un brote de sarampión en el parque de atracciones Disneyland de EEUU. Este brote se inició con el caso de un visitante extranjero infectado y, posteriormente, se declararon hasta 125 casos, que en su mayoría resultaron ser personas no vacunadas. ${ }^{4}$ Es responsabilidad de los profesionales sanitarios actuar sobre ello y tratar de evitar estas situaciones mediante campañas de información y de promoción de las vacunas que traten de contrarrestar las informaciones erróneas lanzadas por los movimientos antivacunas. Se hace evidente la necesidad de una actuación inmediata y la solución no pasa por convertir el cumplimiento del calendario de vacunas sistemáticas en algo obligatorio para los padres, pero sí se ha de entender la primovacunación como un derecho fundamental de los niños. Con una buena 


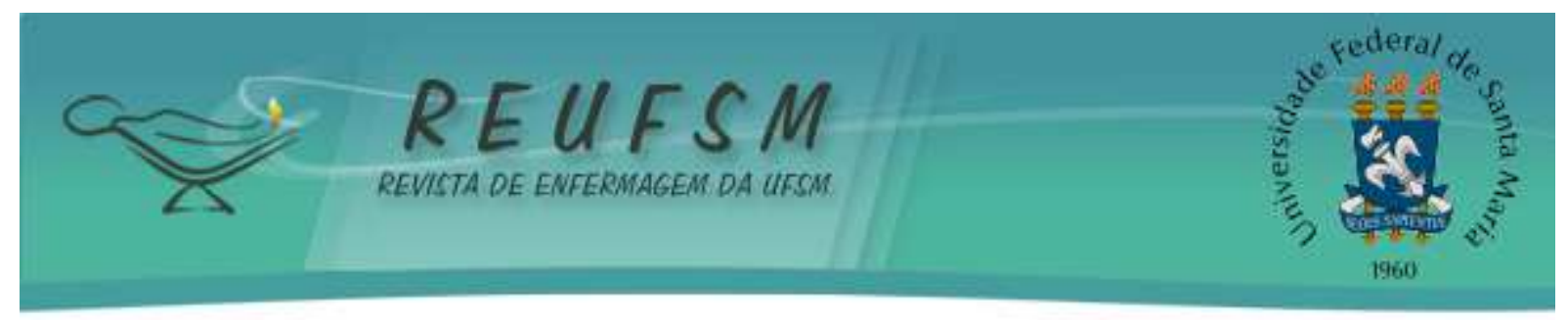

información aportada a los padres por parte de los profesionales sanitarios adecuados pediatras, médicos de familia y enfermeras- mostrándoles los riesgos y beneficios de la vacunación infantil, deben ser ellos los que tomen la decisión de forma responsable. En caso de elegir no vacunar a sus hijos, los padres deberían de firmar un documento en el que asuman todas las consecuencias que pudieran darse. ${ }^{5}$

Para que los profesionales sanitarios actúen en su labor educativa e informativa respecto a la necesidad de vacunación de la población infantil con una mayor eficacia, se hace necesario conocer las informaciones que manejan y transfieren los movimientos anti-vacunas y el estado actual de los mismos. Por ello, y partiendo de la cuestión "¿cómo afecta el movimiento de rechazo a la vacunación en la Salud Pública?”, se ha planteado la realización de la presente revisión de literatura que se marcó como objetivos conocer la situación de estos grupos, comprender mejor los motivos que llevan a las personas a decidir no vacunar a su hijo y conocer la presencia social actual del movimiento anti-vacunas.

\section{MÉTODO}

Se ha realizado una revisión integrativa de la literatura para dar respuesta a la cuestión “¿cómo afecta el movimiento de rechazo a la vacunación en la Salud Pública?”,esto es, para conocer el estado actual del movimiento anti-vacunas, ya que se trata de un tema con complejidad de información y necesidad de revisión por enfoques, es decir, que incluya artículos de diversas metodologías/tipologías (indicado en la Tabla 1). La revisión integrativa busca no solo la definición de conceptos sino también la revisión de teorías, evidencias y revisión de aspectos metodológicos en investigación enfermera. ${ }^{6,7}$ En adición, también señala lagunas en el conocimiento del tema a tratar. ${ }^{6}$

De este modo, se realizó una búsqueda exhaustiva en las bases de datos PubMed, Scientific Electronic Library Online (Scielo), Elservier's Scopus (Scopus), Biblioteca Cochrane Plus y Cumulative Index to Nursing \& Allied Health Literature (CINAHL) durante el periodo de tiempo comprendido entre noviembre de 2015 a mayo de 2016. Como estrategia de búsqueda se combinaron, utilizando los booleanos AND/OR, los siguientes descriptores DeCS/Mesh, tanto en inglés como en español: Vacunas/Vaccines, Vacunación/Vaccination, Negativa al tratamiento/Refusal to treat, Vacunación masiva/Mass vaccination y Padres/Parents.

A su vez, se usaron términos libres para completar las búsquedas, dependiendo de las bases de datos y del volumen de información que recogían: Indecisión vacunal/Vaccine 


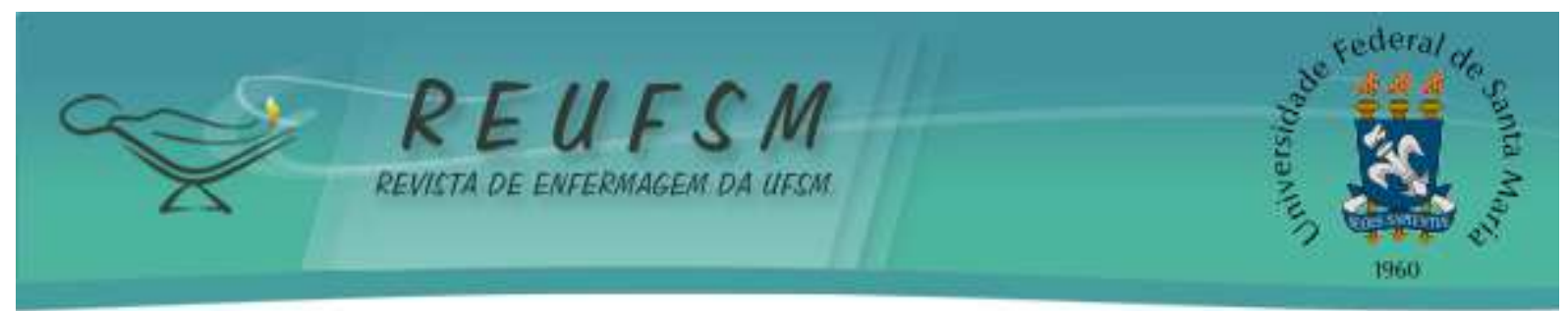

hesitancy, Vacunación infantil/Childhood vaccine, Anti-vacunas/Anti-vaccine,

Rechazo/Refusal, Rechazo de vacunas/Vaccine refusal y Rechazo parental/Refusal parents.

Tabla 1. Estrategias de búsqueda.

\begin{tabular}{|c|c|c|c|c|}
\hline PubMed & Scopus & CINAHL & Cochrane & Scielo \\
\hline $\begin{array}{l}\text { "Childhood } \\
\text { Vaccin*" AND } \\
\text { ("Refusal Parents" } \\
\text { OR "Refusal to } \\
\text { Treat") }\end{array}$ & $\begin{array}{c}\text { "Childhood } \\
\text { Vaccine" AND } \\
\text { ("Refusal Parents" } \\
\text { OR "Refusal to } \\
\text { treat") }\end{array}$ & $\begin{array}{l}\text { "Vaccination" } \\
\text { AND ("Refusal } \\
\text { Parents" OR } \\
\text { "Refusal to treat") }\end{array}$ & $\begin{array}{l}\text { "Rechazo } \\
\text { vacuna" }\end{array}$ & "Vacunación infantil" \\
\hline $\begin{array}{l}\text { "Vaccin*" AND } \\
\text { "Vaccine } \\
\text { hesitancy" AND } \\
\text { "parent*" }\end{array}$ & $\begin{array}{c}\text { ("Vaccin*" OR } \\
\text { "Mass vaccination") } \\
\text { AND "Vaccine } \\
\text { hesitancy" AND } \\
\text { "parents" }\end{array}$ & $\begin{array}{l}\text { "Vaccination" } \\
\text { AND "Vaccine } \\
\text { Hesitancy" }\end{array}$ & & "Anti vacunas" \\
\hline $\begin{array}{l}\text { "Childhood } \\
\text { Vaccine" AND } \\
\text { ("Refusal Parents } \\
\text { OR Hesitancy") }\end{array}$ & $\begin{array}{c}\text { "Childhood } \\
\text { Vaccine" AND } \\
\text { ("Refusal Parents } \\
\text { OR Hesitancy" OR } \\
\text { "Refusal to treat") }\end{array}$ & $\begin{array}{l}\text { (“Anti-Vaccine" } \\
\text { OR "Vaccine } \\
\text { Hesitancy") AND } \\
\text { "Childhood } \\
\text { Vaccin*" }\end{array}$ & & $\begin{array}{l}\text { "Vaccin3" AND } \\
\text { "Vaccine hesitancy" } \\
\text { AND "parents" }\end{array}$ \\
\hline $\begin{array}{l}\text { "Vaccination" } \\
\text { AND ("Refusal" } \\
\text { OR "Anti- } \\
\text { Vaccine") }\end{array}$ & $\begin{array}{l}\text { "Anti-Vaccine" OR } \\
\text { "Vaccine Hesitancy" }\end{array}$ & & & \\
\hline $\begin{array}{l}\text { Límites y filtros: } \\
\text { Idiomas (inglés y } \\
\text { español) } \\
\\
\text { Artículo más } \\
\text { antiguo } \rightarrow 2012 \\
\text { Periodo: Nov. } 2015 \\
\text { a Mayo 2016 }\end{array}$ & $\begin{array}{c}\text { Límites y filtros: } \\
\text { Idiomas (inglés y } \\
\text { español) } \\
\text { Artículo más antiguo } \\
\rightarrow 2012 \\
\text { Periodo: Nov. } 2015 \\
\text { a Mayo } 2016\end{array}$ & $\begin{array}{c}\text { Límites y filtros: } \\
\text { Idiomas (inglés y } \\
\text { español) } \\
\text { Artículo más } \\
\text { antiguo } \rightarrow 2012 \\
\text { Periodo: Nov. } \\
2015 \text { a Mayo } \\
2016\end{array}$ & $\begin{array}{c}\text { Periodo: } \\
\text { Nov. } 2015 \text { a } \\
\text { Mayo } 2016\end{array}$ & $\begin{array}{c}\text { Límites y filtros: } \\
\text { Idiomas (inglés y } \\
\text { español) } \\
\text { Artículo más antiguo } \\
\rightarrow 2012 \\
\text { Periodo: Nov. } 2015 \text { a } \\
\text { Mayo } 2016\end{array}$ \\
\hline
\end{tabular}

Como criterios de exclusión, se rechazaron artículos publicados en idioma diferente a inglés o español, artículos no disponibles en catálogo Fama+, trabajos con título y/o resumen con enfoque no adecuado a este proyecto y, basándonos en la declaración PRISMA ${ }^{8}$ y puesto que el movimiento anti-vacunas constituye un tema cuyo auge es reciente y una problemática social que va cambiando conforme lo va haciendo dicha sociedad, se decidió rechazar trabajos publicados con antigüedad mayor de 5 años para con ello darle la perspectiva más actual. 


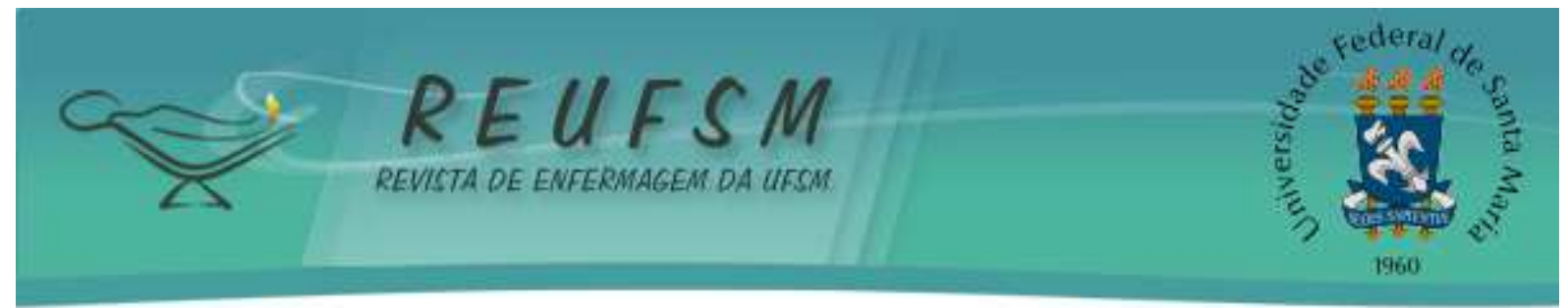

Además, se encontraron artículos hallados de forma repetida en diferentes bases de datos que fueron considerados solo una vez.

Para realizar la revisión de los artículos seleccionados se identificó en el apartado de material y métodos de cada trabajo el diseño empleado, la población de estudio y tamaño muestral en su caso, y los procedimientos empleados, aplicando la escala Scottish Intercollegiate Guidelines Network (SIGN ${ }^{9}$ ) para clasificar los niveles de evidencia de cada trabajo. Se identificaron los resultados y hallazgos principales de cada referencia incluida, en los apartados de resultados y conclusiones, y siempre que tuvieran relación con los objetivos de la presente revisión, se incluyeron para el análisis.

\section{RESULTADOS}

La búsqueda inicial obtuvo como resultado un total de 587 artículos de referencia. Tras aplicar los criterios de exclusión determinados, finalmente fueron seleccionadas 22 referencias para su lectura completa, tal y como se aprecia en el flujograma representado en la figura 1, aplicando los procesos establecidos en la declaración PRISMA. ${ }^{8}$

Figura 1- Flujograma
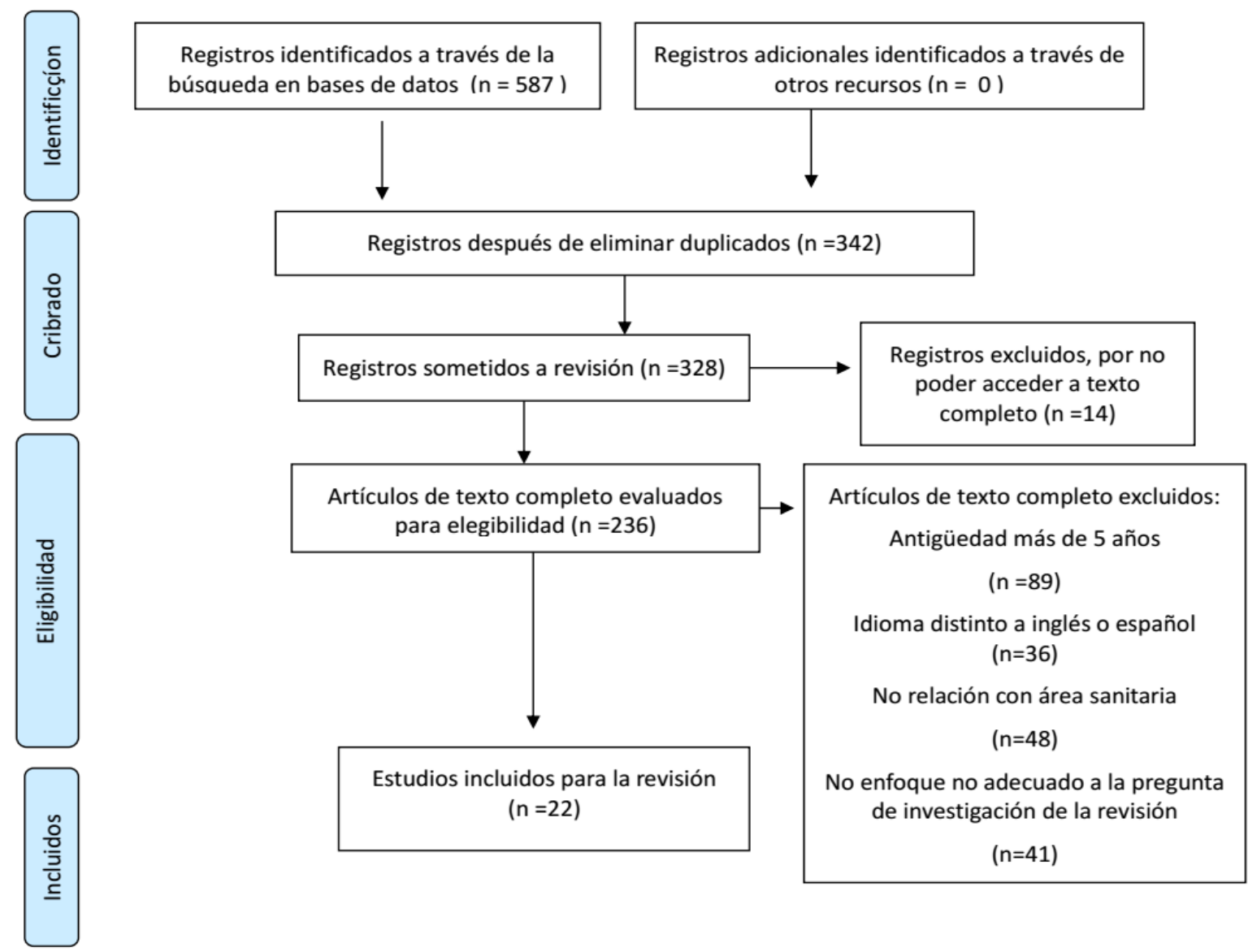


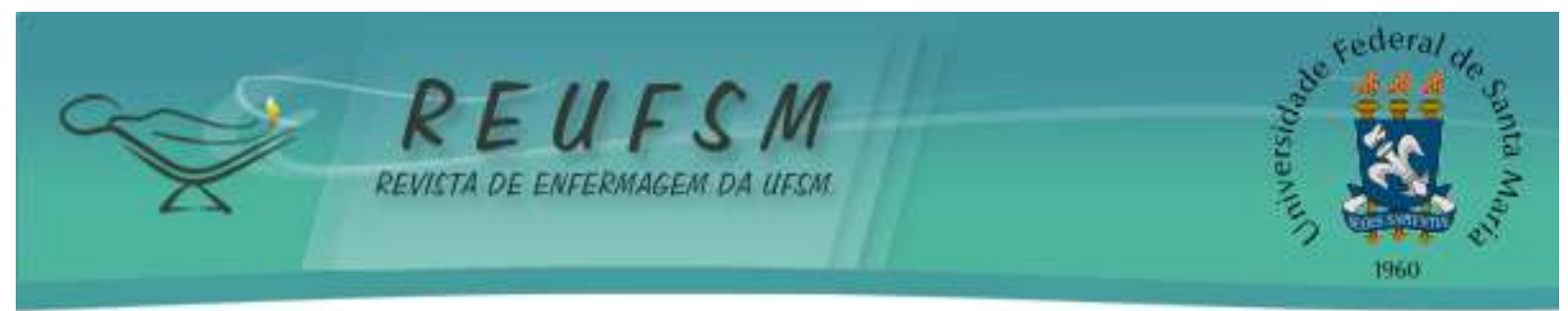

Los artículos incluidos, según la escala SIGN, están catalogados como nivel de evidencia 3, excepto seis de ellos, ${ }^{10-15}$ (cinco con nivel 1 y uno con nivel $4^{12}$ ) tal y como se aprecia en la Tabla 2, que recoge, además, las principales características de los artículos seleccionados para esta revisión. Todos ellos, en menor o mayor medida, hacen una breve introducción sobre la historia o estado de las vacunas y/o los grupos anti-vacunas y sus motivos. Destacan datos llamativos en algunos trabajos, como el número creciente de padres que creen que las vacunas ya no son necesarias. ${ }^{16-18}$

Por otro lado, son muchos los estudios que resaltan la necesidad de crear nuevas estrategias de intervención con enfoques multidisciplinarios 12,14,19-21 potenciando la promoción de la salud. ${ }^{13,14,22}$ Ello pasa por mejorar las habilidades de comunicación de los sanitarios y su relación con los padres. ${ }^{21-24}$ Además, en varios trabajos se intentan conocer mejor las razones que alegan los padres para decir "no" a las vacunas. 15,19, 25, 26

A pesar de que la ciencia actual ha conseguido desmontar los argumentos alegados por los grupos anti-vacunas ${ }^{27}$ sigue siendo aún un motivo de gran relevancia la refutada relación entre autismo y triple vírica. ${ }^{15,26,27}$ Resalta una revisión de literatura ${ }^{28}$ que comprobó la inexistencia de evidencias en las relaciones entre el timerosal y el autismo, y un potente estudio $^{29}$ que simuló la implantación de vacunas obligatorias, pudiéndose conocer los efectos negativos que supondría, obteniendo como resultado lo contrario a lo que se pretendería, aumentar las tasas de vacunación. ${ }^{29}$

Tabla 2 - Principales características de los estudios analizados.

\begin{tabular}{|l|l|c|c|c|c|}
\hline \multicolumn{1}{|c|}{$\begin{array}{c}\text { AUTOR } \\
\text { (PAÍS) }\end{array}$} & $\begin{array}{c}\text { CARACTERÍS- } \\
\text { TICAS Y } \\
\text { TAMAÑ } \\
\text { MUESTRAL }\end{array}$ & $\begin{array}{c}\text { ANO DE } \\
\text { PUBLI- } \\
\text { CACIÓN }\end{array}$ & $\begin{array}{c}\text { NIVEL } \\
\text { DEE } \\
\text { LOGÍA } \\
\text { EVIDEN- } \\
\text { CIA } \\
\text { ESCALA } \\
\text { SIGN }\end{array}$ & HALLAZGOS PRINCIPALES \\
\hline $\begin{array}{l}\text { Harmsen et al. } \\
\text { (Holanda) } \\
\text { 25 }\end{array}$ & $\begin{array}{l}\text { N=60. } \\
\text { Padres holandeses } \\
\text { con al menos un } \\
\text { hijo de entre 0 y } 4 \\
\text { años. }\end{array}$ & 2013 & $\begin{array}{c}\text { Estudio } \\
\text { cualitativo }\end{array}$ & 3 & $\begin{array}{l}\text { Los programas de vacunación } \\
\text { tienen como aspectos positivos su } \\
\text { fácil y libre acceso y la buena } \\
\text { organziación. Como aspectos } \\
\text { negativos, se refieren existir } \\
\text { demasiadas vacunas, inicio a edad } \\
\text { demasiado temprana de la } \\
\text { vacunación y que los padres se } \\
\text { sienten obligados a vacunar por la } \\
\text { influencia social y del Gobierno. }\end{array}$ \\
\hline
\end{tabular}




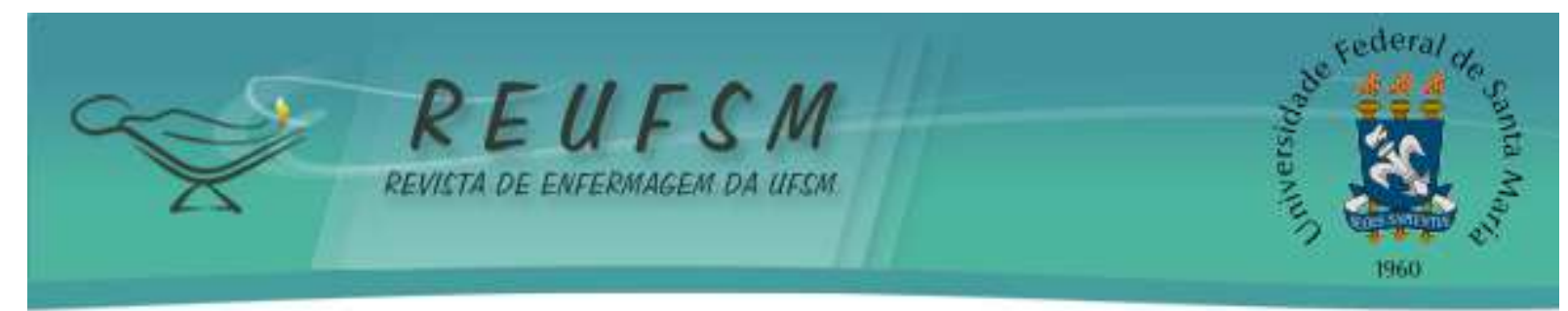

\begin{tabular}{|c|c|c|c|c|c|}
\hline $\begin{array}{l}\text { Dubé y } \\
\text { Laberge } \\
\text { (Canadá) } \\
19\end{array}$ & & 2013 & $\begin{array}{l}\text { Revisión } \\
\text { de la } \\
\text { literatura } \\
\text { narrativa }\end{array}$ & 3 & $\begin{array}{l}\text { Tendencia ascendente de padres que } \\
\text { están indecisos sobre la vacunación. } \\
\text { En la toma de decisión incluyen } \\
\text { factores socio-culturales, } \\
\text { emocionales, espirituales y } \\
\text { políticos. Se necesita más } \\
\text { investigación, formación de los } \\
\text { profesionales y estrategias de } \\
\text { captación para aumentar las tasas de } \\
\text { vacunación. }\end{array}$ \\
\hline $\begin{array}{l}\text { Smith et al. } \\
\text { (EEUU) } \\
16\end{array}$ & $\begin{array}{l}\mathrm{N}=11206 . \\
\text { Padres } \\
\text { estadounidenses } \\
\text { con hijos de entre } \\
24 \text { y } 35 \text { meses de } \\
\text { edad. }\end{array}$ & 2011 & $\begin{array}{c}\text { Estudio } \\
\text { descriptivo } \\
\text { transversal }\end{array}$ & 3 & $\begin{array}{l}\text { El 70'1\% de los padres cree que las } \\
\text { vacunas no son necesarias, El } 71 \% \\
\text { piensa que su hijo podría contraer } \\
\text { una enfermedad por no estar } \\
\text { vacunado y solo el } 50 \% \text { opina que } \\
\text { las vacunas son seguras. }\end{array}$ \\
\hline $\begin{array}{l}\text { Martínez-Diz } \\
\text { et al. (España) } \\
17\end{array}$ & & 2014 & $\begin{array}{l}\text { Estudio } \\
\text { cualitativo }\end{array}$ & 3 & $\begin{array}{l}\text { En la sociedad actual se ha perdido } \\
\text { la percepción de beneficios de las } \\
\text { vacunas frente al riesgo de contraer } \\
\text { la enfermedad, pensándose que } \\
\text { pasar esta infección puede ser } \\
\text { beneficiosa para el sistema } \\
\text { inmunológico. }\end{array}$ \\
\hline $\begin{array}{l}\text { Gilkey et al. } \\
\text { (EEUU) } \\
18\end{array}$ & $\begin{array}{l}\mathrm{N}=1847 . \\
\text { Padres con hijos } \\
\text { de edades } \\
\text { comprendidas } \\
\text { entre } 1 \text { y } 17 \text { años } \\
\text { residentes en } \\
\text { Carolina del } \\
\text { Norte }\end{array}$ & 2013 & $\begin{array}{c}\text { Estudio } \\
\text { descriptivo } \\
\text { transversal }\end{array}$ & 3 & $\begin{array}{l}\text { Un } 12 \% \text { rechaza o retrasa la } \\
\text { vacunación, siendo más común en } \\
\text { prematuros y en padres con } \\
\text { prácticas de vida saludable. Las } \\
\text { razones fueron: } 34 \% \text { preocupación } \\
\text { sobre seguridad de la vacuna, } 15 \% \\
\text { opinan que no son necesarias, } 13 \% \\
\text { opinan que son demasiado pequeños } \\
\text { y el } 10 \% \text { refirió que su hijo estaba } \\
\text { enfermo en el momento de la } \\
\text { vacuna. }\end{array}$ \\
\hline $\begin{array}{l}\text { Glanz et al. } \\
\text { (EEUU) } \\
10\end{array}$ & $\begin{array}{l}\text { N=443. Padres } \\
\text { cuyos hijos no } \\
\text { superaban los } 4 \\
\text { años de edad e } \\
\text { incluidos en el } \\
\text { plan de salud de } \\
\text { la clínica Kaiser } \\
\text { Permante, en } \\
\text { Colorado } \\
\text { (EEUU). }\end{array}$ & 2013 & $\begin{array}{l}\text { Ensayo } \\
\text { clínico } \\
\text { aleatorio }\end{array}$ & 1 & $\begin{array}{l}\text { Surgen tres puntos: 1) el proceso de } \\
\text { toma de decisión comienza antes } \\
\text { del nacimiento, 2) este proceso } \\
\text { cambia, es evolutivo y } 3 \text { ) hay } \\
\text { confianza total en los pediatras, } \\
\text { pero los padres opinan que no dan } \\
\text { información equilibrada sobre } \\
\text { riesgos y beneficios de vacunar. }\end{array}$ \\
\hline $\begin{array}{l}\text { William } \\
\text { (EEUU) } \\
22\end{array}$ & & 2014 & $\begin{array}{l}\text { Revisión } \\
\text { de la } \\
\text { literatura } \\
\text { narrativa }\end{array}$ & 3 & $\begin{array}{l}\text { Se ha demostrado que las razones que los } \\
\text { padres eligen para rechazar o retrasar la } \\
\text { vacunación pueden variar con el tiempo, } \\
\text { por lo que es primordial reevaluar y } \\
\text { abordar estas razones desde la } \\
\text { promoción de la salud. No se ha } \\
\text { investigado lo suficiente sobre la eficacia } \\
\text { y efectividad de las medidas empleadas } \\
\text { por los profesionales sanitarios. }\end{array}$ \\
\hline $\begin{array}{l}\text { Brown et al. } \\
\text { (Reino Unido }\end{array}$ & & 2010 & $\begin{array}{l}\text { Revisión } \\
\text { sistemática }\end{array}$ & 1 & $\begin{array}{l}\text { Los resultados muestran que, } \\
\text { incluso los padres que aceptan la }\end{array}$ \\
\hline
\end{tabular}




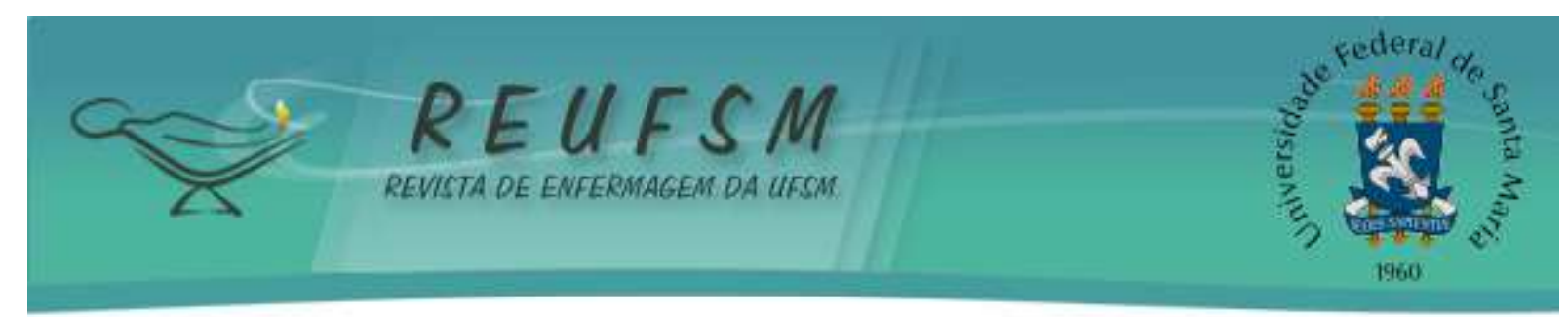

\begin{tabular}{|c|c|c|c|c|c|}
\hline $\begin{array}{l}\text { e Irlanda) } \\
11\end{array}$ & & & & & $\begin{array}{l}\text { vacunación, tienen sus dudas. El } \\
\text { proceso de toma de decisión es } \\
\text { multifactorial y difícil, en el que los } \\
\text { medios de comunicación ejercen un } \\
\text { gran peso, aunque no parece ser } \\
\text { suficiente para decidir. }\end{array}$ \\
\hline $\begin{array}{l}\text { Leask y } \\
\text { Kinnersley } \\
\text { (Australia) } \\
14\end{array}$ & & 2015 & $\begin{array}{l}\text { Revisión } \\
\text { sistemática }\end{array}$ & 1 & $\begin{array}{l}\text { Hay que diferenciar al grupo de } \\
\text { niños que no reciben su } \\
\text { primovacunación por motivos } \\
\text { ideológicos de aquellos que no la } \\
\text { reciben por dificultades de acceso. } \\
\text { Por tanto, se requieren medidas } \\
\text { estratégicas para abordar dicho } \\
\text { rechazo desde los dos puntos. }\end{array}$ \\
\hline $\begin{array}{l}\text { Kentesbaum y } \\
\text { Feemster } \\
\text { (EEUU) } \\
20\end{array}$ & & 2015 & $\begin{array}{l}\text { Revisión } \\
\text { de la } \\
\text { literatura } \\
\text { narrativa }\end{array}$ & 3 & $\begin{array}{l}\text { Es necesario desarrollar estrategias } \\
\text { más efectivas para abordar a los } \\
\text { grupos de padres indecisos con un } \\
\text { enfoque multifacético. }\end{array}$ \\
\hline $\begin{array}{l}\text { Danchin y } \\
\text { Nolan (EEUU) } \\
21\end{array}$ & & 2014 & $\begin{array}{l}\text { Revisión } \\
\text { de la } \\
\text { literatura }\end{array}$ & 3 & $\begin{array}{l}\text { Estrategias de comunicación claras } \\
\text { y flexibles son el punto clave para } \\
\text { hacer frente a la indecisón sobre las } \\
\text { vacunas. }\end{array}$ \\
\hline $\begin{array}{l}\text { William et al. } \\
\text { (EEUU) } \\
13\end{array}$ & $\begin{array}{l}\mathrm{N}=369 . \\
\text { Padres con hijos } \\
\text { lactantes menores } \\
\text { de } 30 \text { días, con } \\
\text { periodo de } \\
\text { gestacion superior } \\
\text { a } 36 \text { semanas, } \\
\text { atendidos en dos } \\
\text { centros de salud } \\
\text { de Tennessee. }\end{array}$ & 2013 & $\begin{array}{l}\text { Ensayo } \\
\text { clínico } \\
\text { aleatorio }\end{array}$ & 1 & $\begin{array}{l}\text { Se detectaron } 132 \text { padres indecisos. } \\
\text { Se dividieron en } 2 \text { grupos: un grupo } \\
\text { control y otro de intervención que } \\
\text { recibió educación sobre las vacunas } \\
\text { durante } 2 \text { meses. Se reevaluó y se } \\
\text { redujo la indecisión sobre las } \\
\text { vacunas en el grupo de intervención } \\
\text { en una media de } 6,7 \text { puntos } \\
\text { (p=0,049), optando } \\
\text { mayoritariamente por las vacunas. }\end{array}$ \\
\hline $\begin{array}{l}\text { Leask } \\
\text { (Australia y } \\
\text { Reino Unido) } \\
12\end{array}$ & & 2015 & $\begin{array}{l}\text { Opinión de } \\
\text { los } \\
\text { expertos }\end{array}$ & 4 & $\begin{array}{l}\text { Hay que combatir el problema, no a } \\
\text { los oponentes. Por tanto, no hay que } \\
\text { enfrentarse a los activistas, sino } \\
\text { realizar actividades de promoción } \\
\text { de la salud para aumentar las tasas } \\
\text { de vacunación. Las actividades } \\
\text { dirigidas hacia ellos podrían } \\
\text { aumentar su publicidad o mensaje. }\end{array}$ \\
\hline $\begin{array}{l}\text { García- } \\
\text { Fernández et } \\
\text { al. (Perú) } \\
28 \\
\end{array}$ & & 2013 & $\begin{array}{l}\text { Revisión } \\
\text { de la } \\
\text { literatura } \\
\text { narrativa } \\
\end{array}$ & 3 & $\begin{array}{l}\text { La evidencia científica concluye } \\
\text { que no hay relación entre el } \\
\text { timerosal y el autismo. }\end{array}$ \\
\hline $\begin{array}{l}\text { López- } \\
\text { Santamaría } \\
\text { (España) } \\
30\end{array}$ & & 2015 & $\begin{array}{l}\text { Estudio } \\
\text { descriptivo } \\
\text { trasnversal }\end{array}$ & 3 & $\begin{array}{l}\text { En España, la probabilidad de } \\
\text { encontrar en internet páginas con } \\
\text { información contraria a la } \\
\text { vacunación es del } 3 \%, \text { mientras que } \\
\text { otros países oscila del } 17 \text { al } 71 \% \text {. }\end{array}$ \\
\hline $\begin{array}{l}\text { Cáceres- } \\
\text { Bermejo } \\
\text { (España) } \\
27\end{array}$ & & 2012 & $\begin{array}{l}\text { Revisión } \\
\text { de la } \\
\text { literatura } \\
\text { narrativa }\end{array}$ & 3 & $\begin{array}{l}\text { Los argumentos alegados por el } \\
\text { movimiento antivacunas han sido } \\
\text { desmontados por la ciencia. Gracias a las } \\
\text { vacunas se evitan alrededor de } \\
2,5 \text { millones de muertes en menores de } 5 \\
\text { años. }\end{array}$ \\
\hline
\end{tabular}




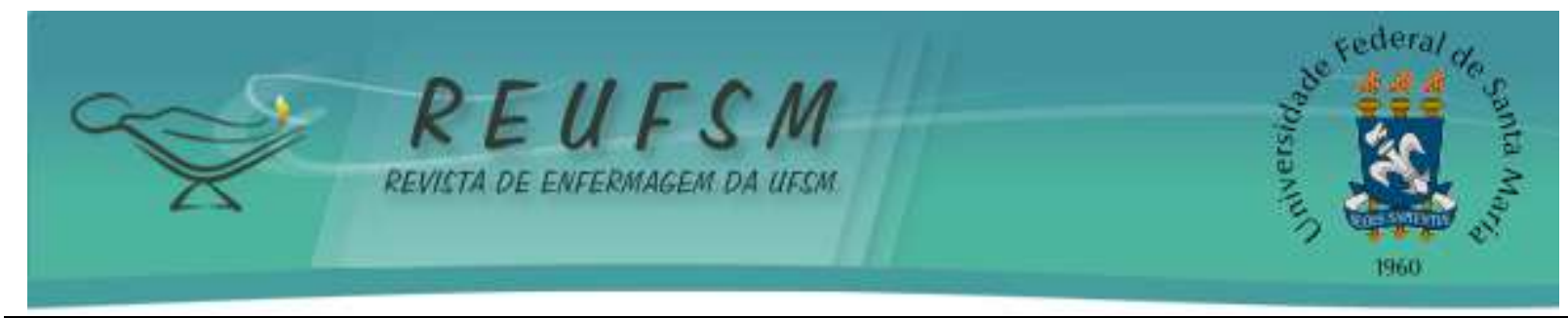

\begin{tabular}{|c|c|c|c|c|c|}
\hline $\begin{array}{l}\text { Luthy et al. } \\
\text { (EEUU) } \\
26\end{array}$ & $\begin{array}{l}\mathrm{N}=801 \\
\text { Padres voluntarios } \\
\text { de todo el } \\
\text { condado de Utah } \\
\text { (EEUU) cuyos } \\
\text { hijos estaban a } \\
\text { punto de entrar en } \\
\text { escuelas donde se } \\
\text { exige estar } \\
\text { vacunados o un } \\
\text { documento legal } \\
\text { sobre el motivo de } \\
\text { no vacunación. }\end{array}$ & 2013 & $\begin{array}{l}\text { Estudio } \\
\text { descriptivo } \\
\text { transversal }\end{array}$ & 3 & $\begin{array}{l}\text { Los participantes responden a un } \\
\text { cuestionario sobre sus motivos para } \\
\text { rechazar la vacunación, siendo el } \\
\text { motivo mayoritario para tal rechazo } \\
\text { "conflicto con creencias } \\
\text { filosóficas". Además, la mayoría de } \\
\text { los padres refieren que no utilizaron } \\
\text { Internet cuando buscaron } \\
\text { información sobre las vacunas. }\end{array}$ \\
\hline $\begin{array}{l}\text { Fefferman y } \\
\text { Nauvoma } \\
\text { (EEUU) } \\
31\end{array}$ & & 2015 & $\begin{array}{l}\text { Estudio } \\
\text { descriptivo }\end{array}$ & 3 & $\begin{array}{l}\text { Se ha demostrado que con la } \\
\text { vacunación aumenta la prevención } \\
\text { de las enfermedades, pero a la vez } \\
\text { provocan que aumente la gravedad } \\
\text { de los casos de nuevos contagios. } \\
\text { En la actualidad, la severidad es } \\
\text { hasta } 5 \text { veces mayor o peor para el } \\
\text { sarampión, } 2 \text { veces peor en la } \\
\text { varicela y hasta } 8 \text { veces más severa } \\
\text { es la rubéola. }\end{array}$ \\
\hline $\begin{array}{l}\text { Blendell y } \\
\text { Fehr (EEUU) } \\
23\end{array}$ & & 2012 & $\begin{array}{l}\text { Revisión } \\
\text { de la } \\
\text { Literatura } \\
\text { narrativa }\end{array}$ & 3 & $\begin{array}{l}\text { Es necesario que los profesionales } \\
\text { sanitarios se sientan cómodos y } \\
\text { conozcan los riesgos y beneficios de } \\
\text { vacunar o no. }\end{array}$ \\
\hline $\begin{array}{l}\text { Yaqub et al. } \\
\text { (Reino Unido) } \\
24\end{array}$ & & 2014 & $\begin{array}{l}\text { Revisión } \\
\text { de la } \\
\text { literatura } \\
\text { narrativa }\end{array}$ & 3 & $\begin{array}{l}\text { Los padres indecisos forman parte } \\
\text { de una tendencia social en aumento. } \\
\text { Los profesionales sanitarios } \\
\text { encuentran dificultades para } \\
\text { establecer una relación de confianza } \\
\text { con los padres. El problema reside } \\
\text { en la falta de información. }\end{array}$ \\
\hline $\begin{array}{l}\text { Taylor et al. } \\
\text { (Australia) } \\
15\end{array}$ & & 2014 & $\begin{array}{l}\text { Meta- } \\
\text { análisis }\end{array}$ & 1 & $\begin{array}{l}\text { No existe ninguna relación entre la } \\
\text { vacuna triple vírica o el timerosal y } \\
\text { el desarrollo del autismo o trastorno } \\
\text { del espectro autista. }\end{array}$ \\
\hline $\begin{array}{l}\text { Betsch y } \\
\text { Böhm. } \\
\text { (Alemania) } \\
29\end{array}$ & $\begin{array}{l}\mathrm{N}=297 . \\
\text { Los participantes } \\
\text { fueron estudiantes } \\
\text { pertenecientes a } \\
\text { dos universidades } \\
\text { alemanas, bajo la } \\
\text { directriz de la } \\
\text { Fundación } \\
\text { Alemana de } \\
\text { Investigación. }\end{array}$ & 2015 & $\begin{array}{l}\text { Estudio } \\
\text { descriptivo }\end{array}$ & 3 & $\begin{array}{l}\text { El trabajo mostró que, en el } \\
\text { supuesto caso de imposición de } \\
\text { vacunación obligatoria, se producen } \\
\text { sentimientos negativos de rechazo, } \\
\text { mientras que la vacunación no } \\
\text { obligatoria no despierta estos } \\
\text { sentimientos. }\end{array}$ \\
\hline
\end{tabular}




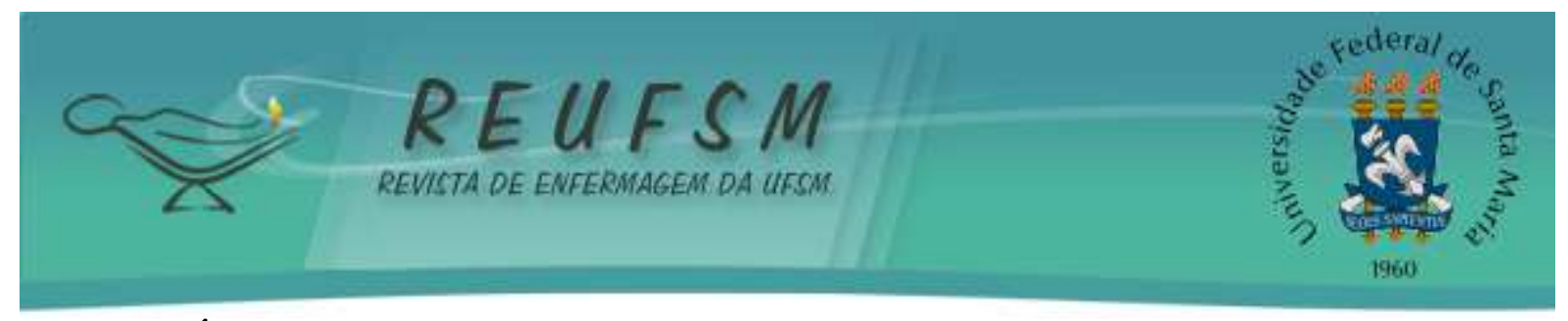

\section{DISCUSIÓN}

Esta revisión sintetiza la información actual del movimiento anti-vacunas, movimiento que es más que una tendencia social, pues surgió en el mismo momento en el que apareció la primera vacuna, ya que a lo largo de la historia de las vacunas fueron muchos los que se mostraron reticentes ante este nuevo descubrimiento en Medicina. ${ }^{12,19,27,30}$ En la realización de este trabajo se encontraron varias limitaciones, principalmente la escasa bibliografía no mayor a 5 años de antigüedad. Debido a esta escasez, fue necesario recurrir a literatura gris, en numerosas ocasiones con dudoso nivel de evidencia. También destaca la imposibilidad de poder llevar a cabo investigaciones experimentales, que proporcionarían mayor nivel de evidencia a los resultados, puesto que las restricciones éticas serían obvias ya que dejar conscientemente una población sin vacunas despertaría conflictos de intereses, además de los riesgos que supondría.

No obstante, la revisión muestra los principales motivos que llevan a los padres a rechazar la vacunación, entre los que destaca lo que puede denominarse un "estilo de vida natural" de los padres. ${ }^{12,14,17-19,21,22,25,26}$ En este caso, los progenitores alegan que las enfermedades inmunoprevenibles son procesos naturales que producen beneficios que ayudan a que el sistema inmunitario se forme y fortalezca. ${ }^{17,25,26}$ Los padres y madres refieren que, realizando otras medidas preventivas basadas en una alimentación natural, aire fresco, realizar ejercicio, etc., unido a unas buenas condiciones de saneamiento, pueden conseguir evitar las enfermedades sin necesidad de vacunar, puesto que es la condición o estado del cuerpo lo que determina la vulnerabilidad ante una enfermedad. ${ }^{17}$ Incluso existen publicaciones ${ }^{31}$ donde tratan de mostrar los peligros o daños sobreañadidos de las vacunas, esto es, el desarrollo de la idea de que al protegerse de las cepas más comunes que causan enfermedades infecciosas, se está provocando a su vez que los agentes invasores busquen otro modo de reproducirse mediante la generación de cepas más virulentas. De este modo, cada vez que los logros sanitarios en vacunas aumentan, también lo hacen los peligros a los que están expuestos aquellos que no reciben esta inmunidad individual. Son las dos caras de las vacunas. ${ }^{31}$

En esta misma línea de motivación para el rechazo a las vacunas, un estudio realizado en Estados Unidos, ${ }^{16}$ muestra que hay una relación directamente proporcional entre los padres que rechazan la vacunación y la preocupación de éstos sobre la nutrición de sus hijos. Así, cuánto más atentos estén los padres a la alimentación de sus hijos, más probable es que rechacen las vacunas. 


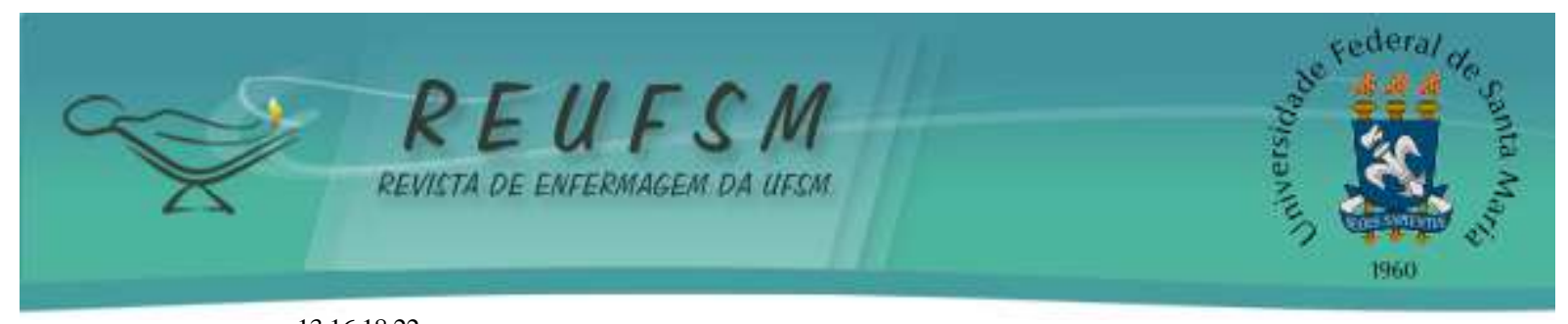

En otros estudios ${ }^{13,16,18,22}$ asocian esta concienciación sobre la alimentación con un mayor nivel socioeconómico de las familias, siendo en general este mayor estatus y/o formación académica de los padres otro factor relevante relacionado con el retraso o rechazo de las vacunas. Sin embargo, no se puede afirmar categóricamente tal relación, puesto que una investigación llevada a cabo entre Irlanda y Reino Unido ${ }^{11}$ concluyó, por el contrario, que un menor nivel académico y menor nivel de ingresos se relacionaban directamente con un mayor rechazo de los programas vacunales, aunque esta asociación tal vez está más justificada por una carencia de recursos, ya sean económicos, sociales o geográficos. ${ }^{12}$

Otro importante motivo para rechazar las vacunas hallado en esta revisión es el temor a los efectos secundarios, a supuestos componentes tóxicos de las vacunas o a la sobrecarga del sistema inmunitario. ${ }^{10,12,14-18,20,24-26,28,31}$ Son muchos los padres que retrasan o rechazan la primovacunación de sus bebés al considerar que éstos no tienen totalmente desarrollado su sistema inmunitario y ven las vacunas como una agresión a dicho sistema. ${ }^{12,25}$ En otros casos, rechazan las vacunas combinadas, ${ }^{16,17,19,25}$ alegando que son demasiadas dosis o que nunca nadie ha enfermado de varias enfermedades infecciosas a la vez. En adición, en un estudio americano $^{21}$ se determinó que uno de cada cuatro padres tenían la creencia errónea de que el sistema inmunológico de sus hijos puede sufrir graves alteraciones debido a una sobrecarga de vacunas. ${ }^{21,23,24,27}$ Este mismo temor por el sistema inmunitario es un factor determinante en padres cuyos hijos son prematuros, ${ }^{18}$ sin saber que, por esa misma razón de prematuridad o bajo peso al nacer, estos niños son más vulnerables a las infecciones y por ello necesitan precisamente estar cubiertos con las vacunas. ${ }^{18}$

En cuanto al temor a los efectos secundarios de las vacunas o derivados por los componentes de las mismas, ${ }^{11,17,18,21,23,25,26,28,30}$ destacan el mercurio y timerosal como componentes que generan más recelo. ${ }^{15,22,23,25,28}$ El timerosal es un compuesto orgánico derivado del mercurio cuya concentración en las vacunas puede variar de 6,25 a 25 microgramos y su acción es evitar la proliferación bacteriana y de hongos en los viales de las vacunas. $^{21}$ A día de hoy, a pesar de que el timerosal ha sido retirado como excipiente ${ }^{19,20,26,27}$ (en 2012 la OMS avaló la seguridad de las vacunas con timerosal, al igual que hizo la Academia Americana de Pediatría en 2013, pero la presión social ha sido tal que tuvieron que retirarlo) ${ }^{28}$ y habiendo pasado casi 20 años del fraude de Wakefield, el miedo a padecer autismo tras la vacuna de la triple vírica, asociado por los detractores de las vacunas al 


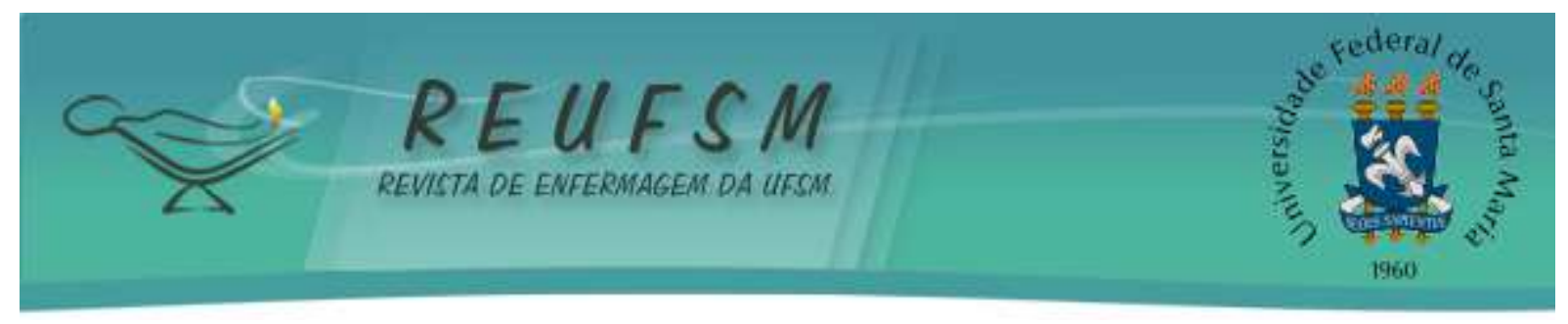

timerosal, sigue estando presente en nuestra sociedad y son muchos los padres que rechazan las vacunas por este motivo, ${ }^{10,19,21,26-29}$ independientemente de haber quedado demostrado que no existe tal relación vacuna-autismo. ${ }^{15,23,26,28,30}$

Otro argumento destacado en los resultados de esta revisión es la desconfianza generada hacia los profesionales sanitarios, hacia las vacunas o hacia las políticas de vacunación. $^{13,16,17,20,21,24,26,30,31}$ En este punto tampoco pasa desapercibido el artículo de Wakefield, puesto que tras la publicación del mismo entraron en juego numerosos factores y ello causó no solo una disminución de las tasas de vacunación de la triple vírica sino que se produjo también una ruptura en la confianza con los profesionales sanitarios..$^{12,20,24,26}$ Por ello, los padres y la población en general, demandan más información ${ }^{11,13,16,17,25,30}$ verídica y objetiva, tanto de las vacunas como de su derecho a rechazarlas. ${ }^{25}$

En menor porcentaje, aunque no por ello menos importantes, se encuentran también otros motivos como las experiencias previas negativas con las vacunas o influencia del entorno social, ${ }^{11,17,20,25,30}$ la presencia de dolor o fiebre tras la vacunación -a pesar de que estas reacciones están incluídas en el consentimiento informado ${ }^{23}$ - la falta de investigación sobre las vacunas, ${ }^{17,21}$ los motivos religiosos (existen religiones que se oponen totalmente a cualquier intervención médica y otras que son contrarias a los componentes de las vacunas ${ }^{19,20}$ ), una errónea creencia sobre la importancia de la vacuna, ${ }^{11,17,25}$ la falsa percepción de gravedad y contagio de la enfermedad, ${ }^{11,25}$ o la idea de que detrás de las vacunas está el interés económico de las empresas farmacéuticas. ${ }^{20,24}$

Un potente trabajo llevado a cabo en $2015,{ }^{29}$ los autores realizaron un experimento en el que se observó el comportamiento de dos grupos ante la simulación de una supuesta implantación de vacunación obligatoria frente a la voluntaria. Los resultados mostraron que, ante la obligatoriedad, los padres incluidos en el grupo de intervención mostraban más sentimientos negativos hacia las vacunas, provocando un aumento del rechazo a la vacunación de un $39 \%$. Estos sentimientos no aparecieron tan claros en el grupo de control, en el que las vacunas eran voluntarias. Por tanto, se interpreta que la obligatoriedad de las vacunas no aumentaría las tasas de vacunación sino que aumentarían los grupos de antivacunas y su actividad para conseguir la libre elección. ${ }^{29}$

Todos estos elementos influyen en las decisiones que deben tomar los padres sobre la vacunación, encontrándose en un punto de controversia en el que no es de extrañar que 


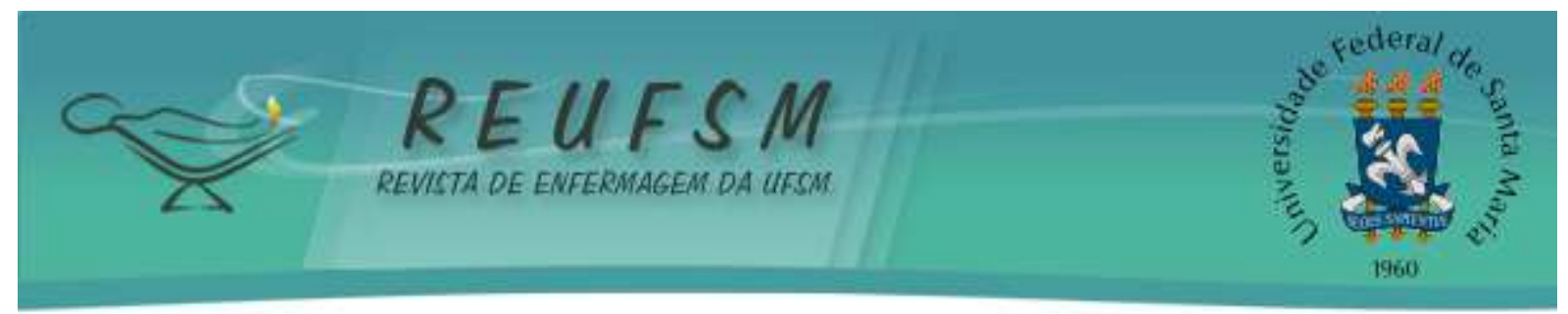

recurran a la red para la búsqueda de información. ${ }^{10,11,17,19,22,23,25,26,30}$ De esta forma, los activistas antivacunas han hecho de internet su medio idóneo para difundir su mensaje. ${ }^{19,23}$ Además, aquellos que acuden a la web desconocen lo errónea que puede ser la información que encuentran, influyendo de manera negativa en su toma de decisiones. ${ }^{19,20,22,25,30}$ Aun así, numerosos estudios muestran que la principal fuente de información para los padres sigue siendo los profesionales sanitarios. ${ }^{10,12,24,28}$ En España, la situación varía ligeramente. Así, destacan estudios donde se llevan a cabo una revisión exhaustiva del contenido de las webs antivacunas $^{30}$ y los resultados muestran que, en nuestro país, la posibilidad de encontrar páginas con contenido anti-vacuna oscila entre un 1 y un $3 \%$, en contraposición con otros países como los anglosajones, donde varía de un $17 \%$ hasta un $71 \% .^{30}$

\section{CONCLUSIONES Y LIMITACIONES}

Tras la realización de la presente revisión, se sacan en claro tres premisas: la primera es que existe confrontación entre la evidencia científica actual y los argumentos de los grupos anti-vacunas, la segunda es que la raíz de este problema radica en una inadecuada información adquirida por padres que comienzan a plantearse la salud de sus hijos y la tercera es que el rol cada vez más participativo del paciente sobre su propio proceso hace que la población demande y busque información sobre vías alternativas, recurriendo a la web, fuente donde la información no es moderada por nadie y puede ser leída por todos.

Así, dado que el problema radica en una inadecuada información, está en manos de los profesionales sanitarios -pediatras, médicos/as de familia y enfermeras/os en concretoactuar sobre ello, con algo tan fácil como informar clara y objetivamente.

Las alternativas pasan, en primer lugar, por aumentar la investigación que refute la seguridad y efectividad de las vacunas. Otra vía que se ha de considerar es la de potenciar la promoción de la salud, realizando actividades dentro de un Programa de Salud que aumente la concienciación de la población, labor similiar a la que realiza anualmente la OMS en la Semana Mundial de la Inmunización, o realizando cambios a nivel gubernamental facilitando el acceso a las vacunas o igualando calendarios vacunales dentro de un mismo país. Además, con el uso de las nuevas tecnologías, recae en los sanitarios una nueva actividad, pues han de estar actualizados para poder indicar fuentes fiables. 


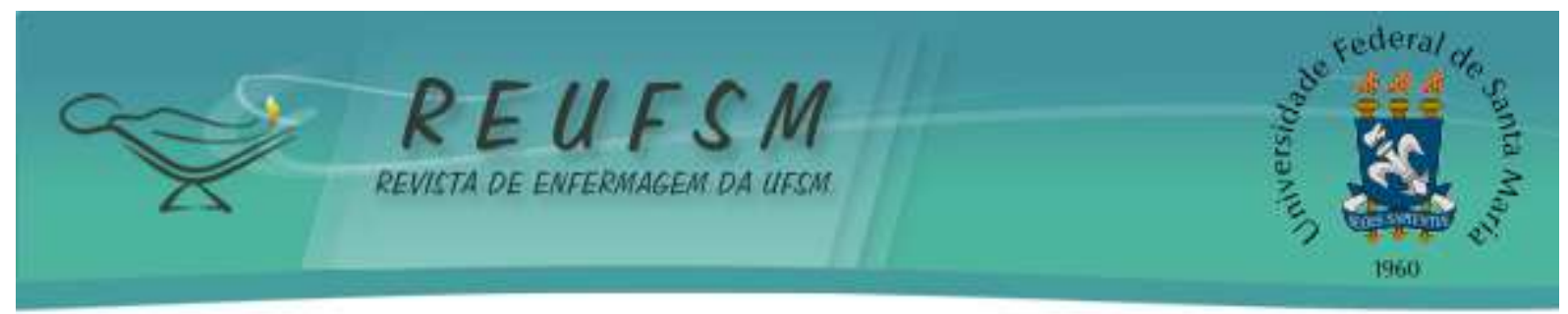

Por ello, es necesario que mejoremos nuestras habilidades en comunicación, con el uso de la empatía y no convertirnos en enemigos de los padres que deciden no vacunar. Hemos de facilitar la toma de decisiones, dejando el camino abierto a una posterior reevaluación de la misma.

\section{LIMITACIONES}

En la realización de este trabajo se encontraron limitaciones, principalmente debido que no se puede llevar a cabo una investigación experimental en la que se estudien dos grupos, puesto que no sería ético además de los riesgos que supondría dejar conscientemente a una población sin vacunar. Por ello, el campo de investigación está muy restringido. De este modo, para realizar esta revisión bibliográfica y definir el tema se encuentra una nueva limitación, pues fue necesario recurrir a páginas con enfoques periodísticos, o de asociaciones o instituciones, todas ellas con poco nivel de evidencia, y no restringirse a la escasa bibliografía adecuada existente en las bases de datos nombradas.

\section{REFERENCIAS}

1. De la Serna, JL. El mentiroso Andrew Wakefield. El Mundo [Internet]. 2015 jun 02 [acesso em $2017 \quad \mathrm{dez} \quad 06]$ Disponível em: http://www.elmundo.es/salud/2015/06/02/556dd4e2ca474178668b4586.html.

2. Segura Benedicto A. La supuesta asociación entre la vacuna triple vírica y el autismo y el rechazo a la vacunación. Gac Sanit [Internet]. 2012 jul-ago [acesso em 2017 dez 06]; 26(4):366-71. Disponível em: http://scielo.isciii.es/scielo.php?script=sci_arttext\&pid=S021391112012000400012 .

3. Asociación de afectadas por la vacuna del papiloma. España. [acesso em 2017 dez 06] Disponível em: http://asociacion.aavp.es/.

4. Aparicio Rodrigo M. Antivacunas: un reto para el pediatra. Rev Pediatr Aten Primaria [Internet]. 2015 abr-jun [acesso em 2017 dez 06];17(66):107-10. Disponível em: http://scielo.isciii.es/scielo.php?script=sci_arttext\&pid=S1139-76322015000300001.

5. Ugarte Libano R. La homeopatía y la AEPap. Rev Pediatr Aten Primaria [Internet]. 2010 jan-mar [acesso em 2017 dez 06];12(45):165-7. Disponível em: http://scielo.isciii.es/pdf/pap/v12n45/carta1.pdf.

6. Mendes KDS, Silveira RCCP, Galvão CM. Revisão integrativa: método de pesquisa para incorporação de evidências na saúde e na enfermagem. Texto \& Contexto Enferm [Internet]. 2008 out-dez [acesso em 2017 dez 07];17(4):758-64. Disponível em: http://www.scielo.br/pdf/tce/v17n4/18.pdf.

7. Soares CB, Hoga LAK, Peduzzi M, Sangaleti C, Yonekura T, Silva DRAD. Integrative review: concepts and methods used in nursing. Rev Esc Enferm USP. 2014 abr;48(2):335-45.

8. Úrrutia G, Bonfill X. Declaración PRISMA: una propuesta para mejorar la publicación de revisions sistemáticas y metaanális. Med Clin [Internet]. 2010 jan [acesso em 2017 dez 


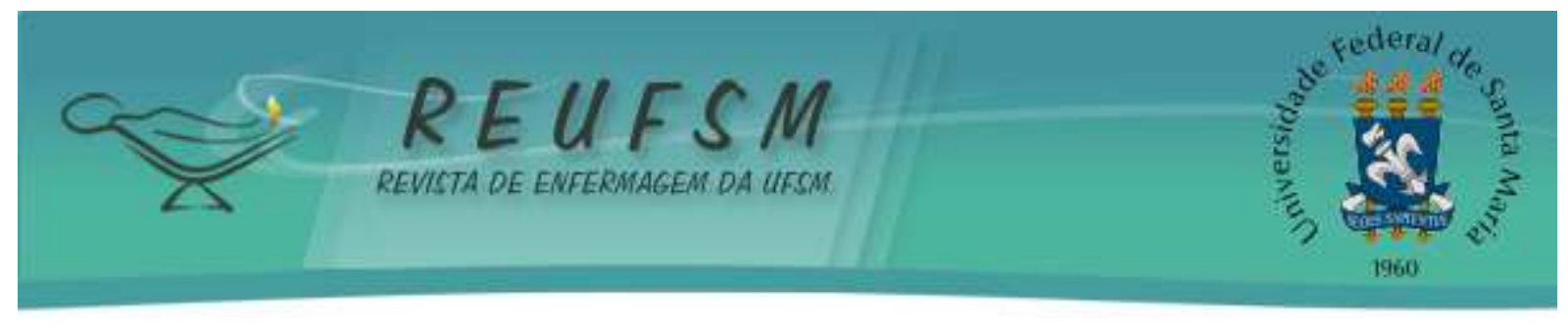

07];135(11):507-11.

Disponível

em:

http://www.laalamedilla.org/Investigacion/Recursos/PRISMA\%20Spanish\%20Sept\%202010.pdf. 9. Harbour R, Miller J. A new system for grading recommendations in evidence based guidelines. BMJ [Internet]. 2001 ago [acesso em 2017 dez 07];323(7308):334-6. Disponível em: https://www.ncbi.nlm.nih.gov/pmc/articles/PMC1120936/.

10. Glanz JM, Wagner NM, Narwaney KJ, Shoup JA, McClure DL, McCormick EV, et al. A mixed methods study of parental vaccine decision making and parent-provider trust. Acad Pediatr [Internet]. 2013 set-out [acesso em $2017 \mathrm{dez}$ 06];13(5):481-8. Disponível em: https://www.ncbi.nlm.nih.gov/pmc/articles/PMC3767928/.

11. Brown KF, Kroll JS, Hudson MJ, Ramsay M, Green J, Long JS, et al. Factors underlying parental decisions about combination childhood vaccination including MMR: a systematic review. Vaccine [Internet]. 2010 jun [acesso em $2017 \mathrm{dez} 06$ ]; 28(26):4235-48. Disponível em: http://www.sciencedirect.com/science/article/pii/S0264410X10005761?via\%3Dihub\#!

12. Leask J. Should we do battle with antivaccination activists? Public Health Res Pract [Internet]. 2015 mar [acesso em $2017 \mathrm{dez}$ 06];25(2):e2521515. Disponível em: http://www.phrp.com.au/issues/march-2015-volume-25-issue-2/should-we-do-battle-withantivaccination-activists/.

13. Williams SE, Rothman RL, Offit PA, Schaffner W, Sullivan M, Edwards KM. A randomized trial to increase acceptance of childhood vaccines by vaccine-hesitant parents: a pilot study. Acad Pediatr [Internet]. 2013 set-out [acesso em 2017 dez 06];13(5):475-80. Disponível em: https://www.ncbi.nlm.nih.gov/pmc/articles/PMC3767934/.

14. Leask J, Kinnersley P. Physician communication with vaccine-hesitant parents: the start, not the end, of the story. Pediatrics [Internet]. 2015 jul [acesso em $2017 \mathrm{dez}$ 06];136(1):180-2. Disponível em: http://pediatrics.aappublications.org/content/136/1/180.

15. Taylor LE, Swerdfeger AL, Eslick GD. Vaccines are not associated with autism: an evidence-based meta-analysis of case-control and cohort studies. Vaccine [Internet]. 2014 jun [acesso em 2017 dez 06];32(29):3623-9. Disponível em: http://www.sciencedirect.com/science/article/pii/S0264410X14006367?via\%3Dihub.

16. Smith PJ, Humiston SG, Marcuse EK, Zhao Z, Dorell CG, Howes C, et al. parental delay or refusal of vaccine doses, childhood vaccination coverage at 24 months of age, and the health belief model. Publich Health Rep [Internet]. 2011 [acesso em $2017 \mathrm{dez}$ 07];126 Supl 2:135-46. Disponível em: https://www.ncbi.nlm.nih.gov/pmc/articles/PMC3113438/.

17. Martínez-Diz S, Martínez Romero M, Fernández-Prada M, Cruz Piqueras, M, Molina Ruano, R, Fernández Sierra, MA. Demands y expectativas de padres y madres que rechazam la vacunación y perspectiva de los profisionales sanitarios sobre la negativa a vacunar. An Pediatr [Internet]. 2014 jun [acesso em $2017 \mathrm{dez}$ 07];80(6):370-8. Disponível em: http://www.analesdepediatria.org/es/demandas-expectativas-padres-madresque/articulo/S1695403313003779/.

18. Gilkey MB, McRee AL, Brewner NT. Forgone vaccination during childhood and adolescence: findings of a statewide survey of parents. Prev Med [Internet]. 2013 mar-abr [acesso em 2017 dez 07];56(3-4):201-6. Disponível em: http://www.sciencedirect.com/science/article/pii/S0091743512006366?via\%3Dihub.

19. Dubé E, Laberge C, Guay M, Bramadat, P, Roy R, Bettinger JA. Vaccine hesitancy: an overview. Hum Vaccin Immunother [Internet]. 2013 ago [acesso em 2017 dez 07];9(8):176373. Disponível em: https://www.ncbi.nlm.nih.gov/pmc/articles/PMC3906279/. 


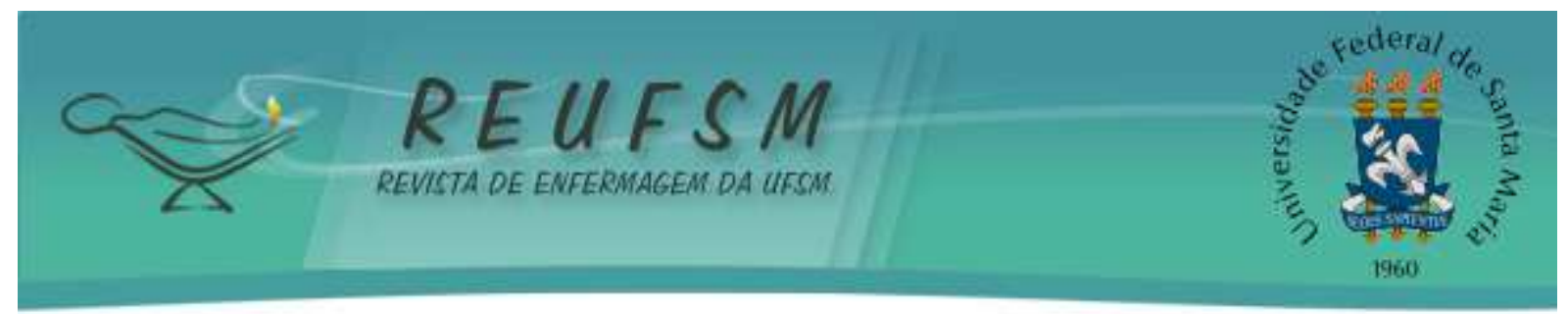

20. Kestenbaum LA, Feemster KA. Identifying and addressing vaccine hesitancy. Pediatr Ann [Internet]. 2015 abr [acesso em 2017 dez 07];44(4):e71-5. Disponível em: https://www.ncbi.nlm.nih.gov/pmc/articles/PMC4475845/.

21. Danchin M, Nolan T. A positive approach to parents with concerns about vaccination for the family physician. Aust Fam Physician [Internet]. 2014 out [acesso em $2017 \mathrm{dez}$ 07]; 43(10):690-4. Disponível em: https://www.racgp.org.au/afp/2014/october/a-positiveapproach-to-parents-with-concerns-about-vaccination-for-the-family-physician/.

22. William SE. What are the factors that contribute to parental vaccine-hesitancy and what can we do about it? Human Vaccin Inmunother [Internet]. 2014 set [acesso em 2017 dez 07];10(9):2584-96.

Disponível

em: https://www.ncbi.nlm.nih.gov/pmc/articles/PMC4977453/.

23. Blendell RL, Fehr JL. Discussing vaccination with concerned patients: an evidence-based resource for healthcare providers. J Perinat Neonatal Nurs [Internet]. 2012 jul [acesso em 2017 dez 07];26(3):230-41. Disponível em: https://insights.ovid.com/pubmed?pmid=22843005.

24. Yaqub O,Castle-Clarke S, Sevdalis N, Chataway J. Attitudes to vaccination: a critical review. Soc Sci Med [Internet]. 2014 jul [acesso em 2017 dez 07];112:1-11. Disponível em: http://www.sciencedirect.com/science/article/pii/S0277953614002421?via\%3Dihub.

25. Harmsen IA, Mollema L, Ruiter RAC, Paulussen TGW, Melker HE, Kok G. Why parents refuse childhood vaccination: a qualitative study using online focus groups. BMC Public Health. 2013 dez; 13:1183.

26. Luthy KE, Beckstrand, RL, Meyers CJH. Common perceptions of parents requesting personal exemption from vaccination. J Sch Nurs [Internet]. 2013 abr [acesso em $2017 \mathrm{dez}$ 07];29(2):95-103. Disponível

em: https://journals.sagepub.com/doi/pdf/10.1177/1059840512455365.

27. Cáceres Bermejo GG. Un momento de reflexión acerca de las vacunas. Sanid Mil [Internet]. 2012 [acesso em 2017 dez 07];68(2):109-14. Disponível em: http://scielo.isciii.es/scielo.php?script=sci_arttext\&pid=S1887-85712012000200009.

28. García-Fernández L, Hernández AV, Suárez Moreno V, Fiestas F. La evidencia acerca de la controversia de las vacunas que contienen timerosal y su asociación con el autismo. Rev Peru Med Exp Salud Publica. 2013;30(2):268-74.

29. Betsch C, Böhm R. Detrimental effects of introducing partial compulsory vaccination: experimental evidence. Eur J Public Health [Internet]. 2016 jun [acesso em 2017 dez 07]:26(3):378-81. Disponível em: https://academic.oup.com/eurpub/article/26/3/378/2467110.

30. López Santamaría MA. Los movimientos antivacunación y su presencia en internet. Ene. 2015;9(3).

31. Fefferman NH, Naumova EN. Dangers of vaccine refusal near the herd immunity threshold: a modelling study. Lancet Infect Dis. 2015 ago;15(8):922-6.

Data de submissão: 28/09/2017

Data de aceite: 10/10/2018

Autor correspondente: Jose Antonio Ponce Blandón

E-mail: japonce@ cruzroja.es

Endereço: Avda. De la Cruz Roja Nº1, duplicado 41009 Sevilla (Espanha)

CEP: - 